\title{
Thoracic Mass Lesions on Imaging: Beware of Tuberculosis Cases
}

\author{
Fatih Meteroglu ${ }^{1}$ and Atalay Sahin ${ }^{2}$ \\ ${ }^{1}$ Department of Thoracic Surgery, Dicle University, Sur / Diyarbakır, Turkey \\ ${ }^{2}$ Department of Thoracic Surgery, Harran University, Sanliurfa, Turkey
}

\begin{abstract}
Tuberculosis (TB) and thoracic malignancy mimic each other clinically, and pose diagnostic challenges. Both diseases are characterised by similar symptoms. We aimed to emphasise that some forms of TB are associated with misleading clinical and radiological manifestations. We present a retrospective study of clinical and pathological results of 10 cases with a preliminary presumptive diagnosis of thoracic malignancy. All patients were found to have TB without evidence of malignancy and were successfully treated with standard antibiotherapy after completion of diagnostic procedures. TB should be considered as a noteworthy differential diagnosis in patients living in TB-endemic countries, and biopsy plays a vital role in correctly diagnosing TB.
\end{abstract}

\section{Key Words: Mass, Neoplasm, Pulmonary, Tuberculosis.}

How to cite this article: Meteroglu F, Sahin A. Thoracic Mass Lesions on Imaging: Beware of Tuberculosis Cases. J Coll Physicians Surg Pak 2021; 31(12):1509-1510.

Tuberculosis (TB) is infamously known to mimic other diseases, especially neoplasms. ${ }^{1}$ TB is reputably capable of inciting various tumoural abnormalities; and the spectrum ranges from nodal enlargement to tumoural lesions. It results unnecessary diagnostic testing and delayed treatment due to the decline of TB incidence in recent times and variable clinical presentations. On the other hand, thoracic malignancy can manifest as benign disease. ${ }^{2}$ Radiological characteristics, typical for malignancy, such as consolidations with irregular borders and thick-walled cavities, showing elevated metabolic activity on positron emission tomography (PET/CT) imaging are also suggestive of thoracic TB. PET/CT is an important functional imaging technique, which is widely used in detecting and evaluating malignancy; and the diagnostic efficacy of PET/CT remains controversial, because it is not a tumour-specific test. ${ }^{3}$ Due to these false-positive results of PET/CT imaging, some TB cases have been erroneously labelled as malignant in previous studies. ${ }^{3} \mathrm{~TB}$ may be seen as pulmonary mass lesions or mediastinal lymphadenopathies in the thorax. The imaging methods are not always accurate.

The pathological study comprises a valuable diagnostic tool. Microbiological tests, such as sputum culture or acid-fast bacilli (AFB) by Ziehl-Neelsen staining, are less valuable and time-consuming.

Correspondence to: Dr. Atalay Sahin, Department of Thoracic Surgery, Harran University, Şanlıurfa, Turkey

E-mail: atalaysahin44@yahoo.com

Received: January 20, 2021; Revised: July 26, 2021;

Accepted: August 14, 2021

DOI: https://doi.org/10.29271/jcpsp.2021.12.1509
The histopathological examination with presence of typical necrotising granulomas with Langhan's giant cells usually assures the correct diagnosis of TB by excluding malignant tumours.

We aimed to report about varied presentations and locations of TB and to emphasise the major diagnostic role of pathology in suchcases. Properhistory, physicalexamination, and histopathological examination are essential in the workup of suspected TB. Early diagnosis and initiation of treatment are important to achieve complete recovery and avoid delays.

We report 10 patients, who were referred to thoracic surgery with a presumptive diagnosis of neoplasm. Sputum culture for AFB and cytology was negative in eight patients, whose lesions were similar to TB on chest imaging findings. Tuberculin skin tests were negative in these patients. The age ranges of the patients were 3-65 years, there was no gender predilection. Two of the patients had a history of smoking. The general characteristics of the patients areshown in Tablel.

Table I: General characteristics of the patients.

\begin{tabular}{|l|c|c|c|c|}
\hline Case & $\begin{array}{c}\text { Age } \\
\text { (years) }\end{array}$ & Gender & Symptoms & $\begin{array}{c}\text { Duration } \\
\text { (months) }\end{array}$ \\
\hline 1 & 62 & Female & $\begin{array}{c}\text { Shortness of breath, anorexia, } \\
\text { weight loss }\end{array}$ & 2 \\
\hline 2 & 53 & Male & Chest pain & 6 \\
\hline 3 & 3 & Female & Coughing & 1 \\
\hline 4 & 65 & Female & $\begin{array}{c}\text { Chest pain, coughing, fatigue, } \\
\text { shortness of breath, }\end{array}$ & 4 \\
\hline 5 & 42 & Male & Fatigue, coughing & 3 \\
\hline 6 & 60 & Female & Painful neck swelling & 12 \\
\hline 7 & 35 & Female & Chest wall pain, swelling & 6 \\
\hline 8 & 30 & Male & Chest pain, swelling & 12 \\
\hline 9 & 25 & Female & Chest pain, coughing, & 4 \\
\hline 10 & 35 & Male & $\begin{array}{c}\text { Coughing, fatigue shortness of } \\
\text { breath }\end{array}$ & 4 \\
\hline
\end{tabular}


Table II: Features of the lesions and diagnostic procedures in the patients.

\begin{tabular}{|c|c|c|c|c|c|}
\hline Case & $\begin{array}{l}\text { Lesion } \\
\text { location }\end{array}$ & \begin{tabular}{|c|} 
Lesion \\
size \\
$(\mathrm{cm})$
\end{tabular} & $\begin{array}{c}\text { CT, } \\
\text { PET/CT }\end{array}$ & Bronchoscopy & $\begin{array}{l}\text { Surgical } \\
\text { procedure }\end{array}$ \\
\hline 1 & $\begin{array}{c}\text { Left lung upper } \\
\text { lobe, LAM }\end{array}$ & 5 &,++ & + & Mediastinoscopy \\
\hline 2 & $\begin{array}{c}\text { Mediastinal } \\
\text { LAM }\end{array}$ & 2 &,+- & + & Mediastinoscopy \\
\hline 3 & $\begin{array}{l}\text { Right lung } \\
\text { lower lobe }\end{array}$ & 2,5 &,+- & & $\begin{array}{l}\text { Wedge } \\
\text { resection }\end{array}$ \\
\hline 4 & $\begin{array}{c}\text { Left lung upper } \\
\text { lobe }\end{array}$ & 5 &,++ & + & Lobectomy \\
\hline 5 & $\begin{array}{l}\text { Right lung } \\
\text { upper lobe }\end{array}$ & 4 &,++ & + & $\begin{array}{l}\text { Wedge } \\
\text { resection }\end{array}$ \\
\hline 6 & $\begin{array}{c}\text { Right retro } \\
\text { sternoclavicular }\end{array}$ & 5 &,+- & & Excision \\
\hline 7 & Right $8^{\text {th }}$ rib & 3 &,+- & & Excision \\
\hline 8 & Left $3^{\text {rd }}$ rib & 3 &,+- & & Excision \\
\hline 9 & $\begin{array}{c}\text { Right } \\
\text { mediastinal } \\
\text { LAM }\end{array}$ & 1,5 &,++ & + & Mediastinoscopy \\
\hline 10 & $\begin{array}{l}\text { Right lung } \\
\text { lower lobe }\end{array}$ & 3 &,++ & + & $\begin{array}{l}\text { Wedge } \\
\text { resection }\end{array}$ \\
\hline
\end{tabular}

The disease had a radiological presentation of a pulmonary nodule in one patient, mediastinal lymphadenomegaly in another one patient, and a single mass lesion in eight patients. The lesions were found in the right lung (30.0\%), in the left lung $(20.0 \%)$, in ribs $(20.0 \%)$ and the mediastinum $(20.0 \%)$. The diseases that mimicked cancer were diagnosed correctly as necrotising granulomatous inflammation via mediastinoscopy in $30.0 \%$, excision in $30.0 \%$, wedge resection in $30.0 \%$, and lobectomy in $10.0 \%$, as shown in Tablell.

TB, as a major cause of morbidity and mortality, remains an important health problem worldwide, particularly in developing countries. Early diagnosis supports effective treatment and leads to reduction of the burden of active TB cases. About 10\% of benign diseases mimic thoracic malignancy on imaging studies. Among infectious diseases, TB is the most common benign disease mimicking lung cancer at initial presentation. ${ }^{4,5}$ The most common clinical presentations related to TB, such as lymphadenopathy, fever, weakness, night sweats, and weight loss, mimic other diseases such as neoplasms or sarcoidosis. ${ }^{5} \mathrm{~A}$ definitive diagnosis cannot be provided on the imaging features in some cases. The diagnosis has to be confirmed by pathological and microbiological tests. The most frequent abnormalities on chest imaging consist of multilobar infiltration, upper lobe infiltration, and pleural effusion. Certain features of lymphadenopathies on CT imaging help differentiate tuberculous from neoplastic causes. ${ }^{6}$ Differentiating thoracic TB from neoplasms can be challenging, according to the clinical and radiological features. Both diseases present parenchymal infiltrations with elevated metabolic activity on PET/CT. Thelater cannot differentiate between malignancy and TB. TB is considered one of the differential diagnoses of PET positive thoracic infiltrations. The activated inflammatory cells, similar to cancer cells, may exhibit markedly increased glycolysis. ${ }^{3}$ The absence of a positive tuberculin test and chest imaging results do not exclude the diagnosis of TB. These cases could easily be misdiagnosed as neoplasms. ${ }^{5}$ Biopsy and pathological examination appear necessary for a definite diagnosis of TB.

TB can easily be confused with malignancy, due to its overlapping clinical and radiological presentation. Pathological examination serves a vital role in TB diagnosis. Thoracic TB should be included in the differential diagnosis of thoracic lesions mimicking malignancy or metastasis.

\section{CONFLICT OF INTEREST:}

The authors declared no conflict of interest.

\section{AUTHORS' CONTRIBUTION:}

FM, AS: Conception or design of the work; or the acquisition, analysis, or interpretation of data for the work; and drafting the work or revising it critically for important intellectual content; and final approval of the version to be published; and agreement to be accountable for all aspects of the work in ensuring that questions related to the accuracy or integrity of any part of the work are appropriately investigated and resolved.

\section{REFERENCES}

1. Hammen I. Tuberculosis mimicking lung cancer. Respir Med Case Rep 2015; 16:45-7. doi: 10.1016/j.rmcr.2015.06.007.

2. Snoeckx A, Dendooven A, Carp L, Desbuquoit D, Spinhoven MJ, Lauwers $P$, et al. Wolf in sheep's clothing: Primary lung cancer mimicking benign entities. Lung Cancer 2017; 112:109-117. doi: 10.1016/j.lungcan.2017.07.037.

3. Niyonkuru A, Bakari KH, Lan X. 18F-fluoro-2-deoxy-dglucose Pet/Computed tomography evaluation of lung cancer in populations with high prevalence of tuberculosis and other granulomatous disease. PET Clin 2018; 13(1):19-31. doi: 10.1016/j.cpet.2017.08.003.

4. Pilaniya V, Gera K, Kunal S, Shah A. Pulmonary tuberculosis masquerading as metastatic lung disease. Eur Respir Rev 2016; 25(139):97-8. doi: 10.1183/16000617.00002315.

5. Dalar L, Sokucu SN, Karasulu AL, Altin S. Tuberculosis can mimic lung cancer: A case series. Turk Toraks Derg 2013; 14:30-5.

6. Engin G, Acuna B, Acuna G, Tunaci M. Imaging of extrapulmonary tuberculosis. Radio Graphics 2000; 20:471-88. 